\title{
Perceptions of Learning versus Teaching Styles
}

\author{
Kamden K. Strunk, Oklahoma State University \\ Diane M. Montgomery, Oklahoma State University
}

Strunk, Ph.D. is an adjunct instructor in the School of Educational Studies and researcher in the Center for Research on STEM Teaching and Learning; Montgomery, Ph.D. is a Regents Professor of Educational Psychology in the School of Applied Health and Educational Psychology.

\begin{abstract}
The student perspective is a missing element in learning research, particularly for preferences in learning according to Sternberg's intelligence theory. This study examined the way that a group of nine students describe their own learning styles and the learning environment of the classes they take by using two sorting procedures. Three viewpoints emerged from the interpretation of the data, which were named Individualized Practical Understanding, Social Imagination, and Reflective Analysis. The emergent viewpoints seem to suggest that a more nuanced understanding of learning occurs within-person.
\end{abstract}

\section{Introduction}

How students learn is a topic of considerable research and debate. One researcher who has written extensively on the subject is Sternberg (c.f., Grigorenko \& Sternberg, 1997; O'Hara \& Sternberg, 2001; Sternberg, 2001; 2004; Sternberg \& Grigorenko, 1993; Sternberg, Grigorenko, \& Zhang, 2008; Sternberg, Reznitskaya, \& Jarvin, 2007; Sternberg \& Zhang, 2005; Zhang \& Sternberg, 2002; Zhang, Sternberg, \& Rayner, 2012). Sternberg describes learning through the conceptual model of thinking styles or intellectual styles or intelligence, which for the purpose of this study are reviewed as analytic, creative, practical, and wisdom. Earlier models exist in Sternberg's writing, but these four were selected for their conceptual integrity and empirical fit in published factor analyses (e.g., Stemberg, Castejon, Prieto, Hautamaki, \& Grigorenko, 2001).

These thinking styles have shown promise as the basis for differentiated instruction (Sternberg \& Zhang, 2005). Additionally, thinking style seems to predict academic performance (Grigorenko \& Sternberg, 1997; Sternberg, 2001; Zhang, 2004). These styles predict interpersonal skills as well, including emotional intelligence (Murphy \& Janeke, 2009). However, research in this area focuses on teachers and their work of teaching. That is, the perspective is taken of the teacher in the classroom. The resulting questions have been centered around how instruction might be differentiated (Sternberg \& Zhang, 2005), how teachers might jdentify and work with different kinds of thinkers (Grigorenko \& Sternberg, 1997; Zhang \& Sternberg, 2002), how students can be induced to use other thinking styles (O'Hara \& Stemberg, 2001), what kinds of styles schools ought to emphasize(Sternberg, 2001; Sternberg, Grigorenko, \& Zhang, 2008; Sternberg, Reznitskaya, \& Jarvin, 2007), and how schools can work with assessment practices considering these intellectual styles (Sternberg, Grigorenko, \& Zhang, 2008).

What is missing from this level of analysis is the perspective of the student. How do students perceive their own learning, in their own understanding? How do students perceive their learning environments? Do students perceive the learning environments in which they are placed as similar or dissimilar from their own learning styles? In the present study, Sternberg's theory was used as a way of thinking about and describing various learning styles. However, the perception of the students of their own learning styles and of their learning environments is the focus of inquiry.

\section{Method}

The methodological approach used in this study for understanding students' perceptions of their learning styles and the learning environment is Q-methodology (Brown, 1980; Stephenson, 1953). Q-methodology provides a unique opportunity to investigate subjective understandings of a particular self-referent phenomenon (e.g., learning; McKeown \& Thomas, 1988). This method provides a glimpse into possible viewpoints (i.e., resultant from factors) 
of a given concourse (i.e., set of possible statements about a phenomenon). That concourse is structured or sampled through the use of theory about what statements might have the most meaning to individuals - in this case, Sternberg's thinking styles. A P-set (i.e., group of participants) is chosen to sort the statements to determine the viewpoints present among that P-set. The data according to the P-set is factor analyzed, rather than the Q-set (or the sample of statements from the concourse) to determine how individuals in the P-set cluster around latent viewpoints, rather than how items cluster around latent factors (McKeown \& Thomas, 1988). This structure of the sorts is then used to calculate the $z$-scores of the statements within the factor. This provides a distinct way of investigating perceptions of learning and learning environments, and how they may be similar or dissimilar within-person.

\section{Participants}

After appropriate IRB approval, undergraduate students were purposively sampled from classes taught by instructors known to the primary researcher. These instructors were asked to think about their class and identify four to six students who seemed to learn differently from one another, and approach them to ask if they would be willing to allow the instructor to pass their information on to the researcher. Nine students participated in this study. The participants' age ranged from 19 to 22 years, and seven were women while two were men. The sample included four Education majors, one Therapeutic Recreation major, one Speech Therapy major, one Psychology major, one History major, and one Agriculture major. In terms of ethnicity, eight participants self-identified as white while one self-identified as African-American. The average reported GPA for participants was 3.61, with a range of 2.7 to 4.0. All participants received extra credit in their courses for participating in the study, and data were collected in the Spring semester of 2013.

\section{Materials}

The materials consisted of a set of 36 statements (see Table 3), a Q-sort board with a range of nine columns $(2,4,4,5,6,5,4,4,2$ spaces, with scoring of $-4,-3,-2,-1,0,1,2,3,4$, respectively). The far left column is labeled 'Most unlike me' and the far right column is labeled 'Most like me'. Sternberg's theory of analytical, practical, creative, and wisdom, with nine statements in each category was used to structure the concourse from which the statements were sampled. The statements were created by adapting items from existing measures of thinking style to make them more self-referent, as well as by writing new items to reflect the content of each thinking style. Statements were balanced between the four thinking styles among the 36 statements so there were nine for each thinking style.

\section{Procedure}

The sorting occurred individually and each participant was given instructions on how to sort, beginning with sorting all statements into three general piles of 'most unlike', 'most like', and those they did not have strong feelings about. Following that initial read participants were instructed to place the two they felt were the most like them in the 'most like' column on the Q-sort board. Then, they repeated this for the 'most unlike' column. This back-and-forth procedure was repeated until all statements were placed on the board. Participants completed this procedure for each of the two conditions of instruction, "How do you learn?" and, "How are your classes taught?" The first question was designed to investigate students' perception of their own learning style, and the second to investigate their perception of their learning environments. After completing both sorts, the participant filled out the demographics questionnaire, which included an open-ended question to encourage other descriptions of learning and teaching processes. 


\section{Results}

Both sorts for each participant were entered together in the analysis. Data were analyzed in PQMethod using Principal Components Analysis (PCA) with Varimax rotation. With three components, there was only one confounded sort (a sort which achieved significance on more than one factor) and no sorts without significant loadings using the .45 level of significance. Factor loadings for each sort with an indication of those used for the z-score calculation (defining sorts) can be found in Table 1. This rotation resulted in six defining sorts on the first factor, five on the second, and six on the third.

Table 1 Factor Loadings on Rotated Matrix

\begin{tabular}{llll}
\hline Sort & Factor 1 & Factor 2 & Factor 3 \\
\hline 19, F, Education, Learn & $\mathbf{*} \mathbf{0 . 7 4 7 7}$ & 0.153 & 0.0243 \\
19, F, Education, Taught & $\mathbf{* 0 . 5 7 1 0}$ & 0.2942 & 0.3618 \\
\hline 21, F, Education, Learn & $\mathbf{* 0 . 5 6 0 7}$ & 0.3134 & 0.2416 \\
21, F, Education, Taught & 0.4023 & 0.1546 & $* \mathbf{0 . 6 0 3 9}$ \\
\hline 22, F, Education, Learn & -0.0482 & 0.4398 & 0.0703 \\
22, F, Education, Taught & -0.1295 & 0.3131 & $* \mathbf{0 . 6 5 2 7}$ \\
\hline 20, F, Ther Rec, Learn & -0.1775 & $* \mathbf{0 . 5 0 4 5}$ & 0.0119 \\
20, F, Ther Rec, Taught & $\mathbf{* 0 . 5 6 8 8}$ & -0.217 & 0.0553 \\
\hline 21, F, Psych, Learn & 0.1584 & 0.3145 & $* \mathbf{0 . 5 6 2 7}$ \\
21, F, Psych, Taught & $* \mathbf{0 . 5 4 6 9}$ & $-\mathbf{0 . 3 4 5 5}$ & -0.0249 \\
\hline 22, M, History, Learn & -0.0103 & -0.0976 & $* \mathbf{0 . 7 6 6 4}$ \\
22, M, History, Taught & 0.0073 & -0.1749 & $* \mathbf{0 . 6 9 2 1}$ \\
\hline 21, M, Ag, Learn & 0.3043 & $\mathbf{* 0 . 7 9 8 1}$ & 0.0274 \\
21, M, Ag, Taught & $* \mathbf{0 . 7 8 4 3}$ & -0.2345 & 0.0427 \\
\hline 20, F, Education, Learn & 0.0602 & $\mathbf{* 0 . 7 6 0 6}$ & 0.085 \\
20, F, Education Taught & 0.2339 & 0.0293 & $* \mathbf{0 . 6 5 4 1}$ \\
\hline 20, F, Sp Ther, Learn & 0.3988 & $\mathbf{* 0 . 5 5 1 3}$ & 0.2815 \\
20, F, Sp Ther, Taugh & 0.2964 & $* \mathbf{- 0 . 7 7 5 6}$ & 0.1025 \\
\hline
\end{tabular}

Note. $\mathrm{A} *$ denotes a defining sort.

Next three visual displays of all data comparisons, called our mockups, were created using the $z$-scores for each statement for each factor. The z-score is the mean position of that statement for those loading on the factor, or combined, for that viewpoint. These statements, comparisons across factors, demographic information, and responses to the open-ended questions were then interpreted for their meaning in relative position to one another in order to understand the qualitative meaning of each viewpoint in terms of learning styles and students perceptions of them. For a full list of statements and their z-score on each viewpoint, see Table 3. 


\begin{tabular}{|c|c|c|c|}
\hline Statement & 1 & 2 & 3 \\
\hline Analyze problems and issues related to course content & .98 & -.32 & -.06 \\
\hline Analyze complex problems in the field & 1.19 & -1.17 & -.92 \\
\hline Critique design or arguments made by others on a given topic & .58 & -.11 & -.69 \\
\hline Judge the quality of work for strengths and weaknesses & -.29 & .00 & 1.04 \\
\hline Compare and contrast two important theories in the area & 1.14 & -1.23 & 1.06 \\
\hline $\begin{array}{l}\text { Evaluate the validity of an argument, its strengths, and } \\
\text { weaknesses }\end{array}$ & 1.06 & 1.06 & .78 \\
\hline Assess the strategy used while observing a situation & .85 & -.63 & -.50 \\
\hline Think about differences and similarities among concepts & -.20 & -.97 & 1.08 \\
\hline Examine an argument describing its merits and problems & -.13 & -.38 & 1.51 \\
\hline Create a new application for information presented in class & -.90 & .13 & -1.34 \\
\hline Invent a different way of describing an issue in your field & -2.14 & -1.23 & -1.23 \\
\hline $\begin{array}{l}\text { Discover a brand new concept that explains other problems in } \\
\text { your field }\end{array}$ & -1.46 & -1.19 & -.60 \\
\hline $\begin{array}{l}\text { Imagine a future situation and come up with a response to } \\
\text { that situation }\end{array}$ & .28 & 1.19 & .56 \\
\hline Suppose a hypothetical problem and come up with a solution & .47 & -1.75 & .03 \\
\hline Predict changes in your career field in the next 20 years & -.56 & 1.35 & -1.82 \\
\hline Create and describe an innovative use of existing ideas & .48 & -1.08 & -1.57 \\
\hline Invent a new artistic expression for existing concepts & -2.40 & -.54 & -1.69 \\
\hline $\begin{array}{l}\text { Imagine yourself in a career field and create solutions to } \\
\text { problems you will face }\end{array}$ & .22 & 1.65 & -.72 \\
\hline Apply class knowledge to concrete problems & 1.85 & -.28 & .00 \\
\hline Use your knowledge to understand a real-life situation & 1.14 & 1.52 & 1.15 \\
\hline $\begin{array}{l}\text { Put into practice your conceptual knowledge to help your } \\
\text { team at work succeed }\end{array}$ & .21 & .85 & -.22 \\
\hline $\begin{array}{l}\text { Implement a plan you write in class to an actual work } \\
\text { environment }\end{array}$ & .22 & .08 & -1.25 \\
\hline Employ concepts you learn in class on authentic problems & .90 & -.24 & .71 \\
\hline $\begin{array}{l}\text { Render practical a design you create in class by adapting it to } \\
\text { a new context }\end{array}$ & -1.17 & -.98 & -.56 \\
\hline $\begin{array}{l}\text { Apply concepts learned in class by solving a problem in your } \\
\text { daily life }\end{array}$ & .40 & 1.49 & -.49 \\
\hline $\begin{array}{l}\text { Make a plan of action based on concepts or theories presented } \\
\text { in class }\end{array}$ & .75 & -.93 & -.71 \\
\hline Think about career applications of the ideas learned in class & .80 & 1.13 & -.20 \\
\hline Role-modeling learning and decision making for others & -1.09 & .85 & .95 \\
\hline Learning to balance self-interest and the interests of others & -1.04 & .56 & -.33 \\
\hline Understanding and critiquing the values in decision making & -.56 & -.12 & .18 \\
\hline $\begin{array}{l}\text { Searching for ways to serve the common good with the } \\
\text { course material }\end{array}$ & -1.35 & 1.11 & .41 \\
\hline Reflecting on life's experiences relevant to current learning & -.20 & 1.17 & 1.22 \\
\hline Learning cooperatively with others for a common goal & -.60 & 1.20 & 1.28 \\
\hline Examining the way solutions and questions evolve over time & -.34 & -.82 & -.17 \\
\hline Understanding multiple points of view on a particular topic & 1.21 & -.10 & 1.86 \\
\hline $\begin{array}{l}\text { Analyzing and understanding decision making from multiple } \\
\text { perspectives }\end{array}$ & -.28 & -1.28 & 1.30 \\
\hline
\end{tabular}

\section{Viewpoint One: Individualized Practical Understanding}

This viewpoint included an even mixture of defining sorts that were in the learn (3) and are taught (3) conditions. This viewpoint was marked by an analytic quality, rooted in concrete 
problems from the field. This interpretation is supported by their strong assessments to the following feelings:

- Apply class knowledge to concrete problems ( +4 , the position on the sorting board for the results for this viewpoint)

- Analyze complex problems in the field $(+2)$

This learning, however, is not perceived to be social in nature. This lack of a social nature to learning is supported by the placement of these statements in the Most disagree columns:

- Searching for ways to serve th common good with the course material (-3)

- Role-modeling learning and decision making for others (-3)

- Learning cooperatively with others for a common goal (-2)

Finally, the interpretation of this viewpoint as emphasizing a practical understanding is supported by the view that these sorts express that invention is unlike learning for both how they prefer to learn and the environment in which learning occurs:

- Invent a different way of describing an issue in your field (-4)

o Invent an entirely new artistic expression for existing concepts $(-4)$

\section{Viewpoint Two: Social Imagination}

Defining sorts in this viewpoint represent learning as a social process as interpreted from these statements to which the sorters agreed:

o Learning cooperatively with others for a common goal $(+3)$

- Searching for ways to serve the common good with the course materials $(+2)$.

However, they also view learning as an imaginative process with these statements as most like their style of learning:

- Imagine yourself in a career field and create solutions to problems you will face $(+4)$

- Imagine a future situation and come up with a response to that situation $(+3)$

- Predict changes in your career field in the next 20 years $(+3)$

However, for this viewpoint, the imagination is rooted in social consequences:

- Use your knowledge to understand a real-life situation $(+4)$

- Apply concepts in class by solving a problem in daily life $(+3)$

This points to the practicality of their imaginative learning, which is deeply social as highlighted by their view of social learning items as 'most like' their way of learning. Finally, this social, imaginative style of learning is not abstract or hypothetical, but has real application in the social world. Items unlike their view:

- Suppose a hypothetical problem and come up with a solution (-4)

- Compare and contrast two important theories in the content area $(-3)$

- Invent a different way of describing an issue in your field $(-3)$

This shows a preference for learning that is applicable in real terms in the current social reality rather than in the abstract or the hypothetical. It is worth noting that this viewpoint included four learn sorts and only one are taught sorts, indicating it may be more of an ideal type for students (i.e., "I really want to learn this way, but my classrooms do not work that way.") but a deeper analysis of incongruence between student learning style and perception of classroom environment is included later. 


\section{Viewpoint Three: Reflective Analysis}

This viewpoint shows a clear pattern of preference for comparison and analysis as evidenced by the agreement to:

- Understanding multiple points of view on a particular topic $(+4)$

- Examine an argument describing its merits and potential problems (+4)

o Analyzing and understanding decision making from multiple perspectives $(+3)$

However, application of knowledge is strongly unlike this view:

- Predict changes in your career field in the next 20 years $(-4)$

- Create a new application for information presented in class $(-3)$

o Implement a plan you write in class to an actual work environment $(-3)$

This contrast of analyzing and understanding as 'most like' and application as 'most unlike' leads to an interpretation of the viewpoint as emphasizing a reflective analysis. This viewpoint included two learn conditions, and four are taught conditions.

(In)congruence Between Perceptions of Learning Style and Learning Environments The descriptive analysis of the perceived congruence and incongruence between students' learning style and how they perceive their classes to be taught shown that only three of the nine participants perceived their learning style similarly to their perception of how their classes were taught. For a table demonstrating these differences, see Table 2. 
Table 2

Comparison of Factor Loadings on Condition of Instruction by

1. Participant

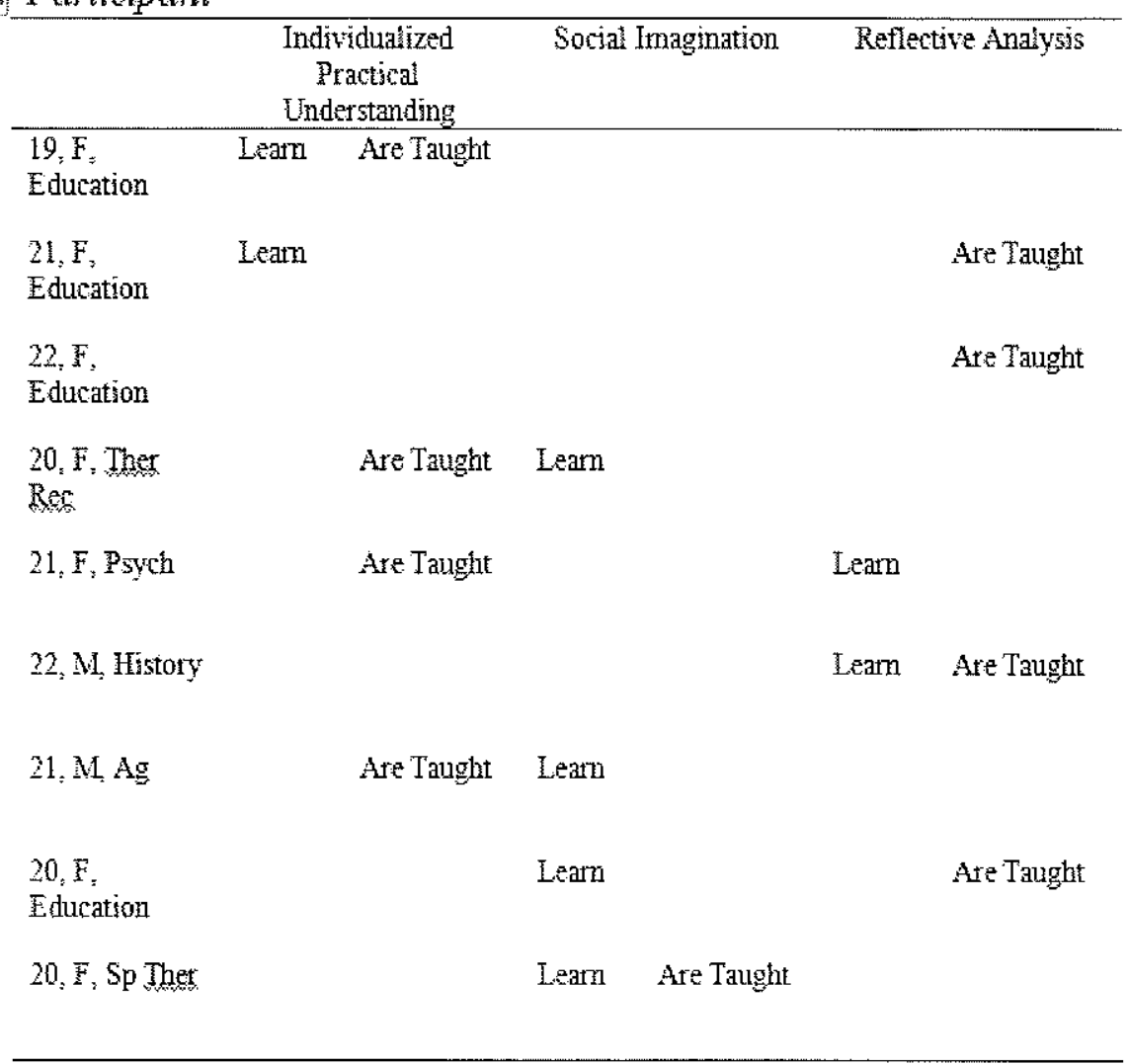

\section{Sternberg's Theory and Student Viewpoints}

In order to understand how the emergent viewpoints overlapped and did not overlap with Sternberg's thinking styles, a descriptive comparison was conducted. In comparing the viewpoints to the originally structured thinking styles, there is some overlap, but it is limited (See Figure 1). For example, it is possible to interpret a strong practical and social element in Viewpoint 1, a de-emphasis on analysis and preference for wisdom in Viewpoint 2, and preference for wisdom and analysis in Viewpoint 3 with de-emphasis on creativity. However, these are more supportive of the viewpoint interpretations than they are instructive or informative regarding Sternberg's thinking styles. That is, these emergent viewpoints are not particularly supportive of the four thinking styles, but the thinking styles are useful in thinking about the viewpoints that emerged from the data.

Academic Exchange Quarterly - Spring 2013

Copyright $(\mathbb{C}$ authors - details inside back cover 


\section{Figure 1}

Comparison of Sternberg's Thinking Styles to Viewpoints

Viewpoint 1: Individualized Practical Understanding

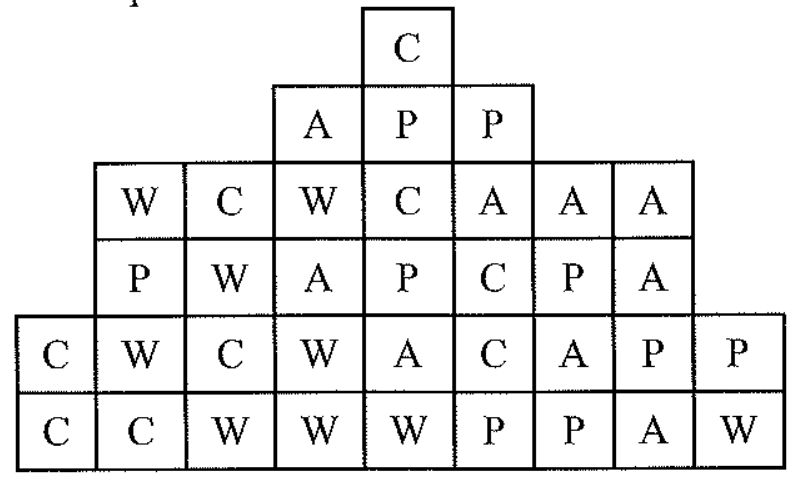

Viewpoint 2: Social Imagination

\begin{tabular}{|c|c|c|c|c|c|c|c|c|}
\hline \multicolumn{4}{|c|}{ P } & A & & & & \\
\hline & & & $\mathrm{A}$ & W & $P$ & & & \\
\hline & A & $P$ & A & A & $\overline{\mathrm{W}}$ & $\mathrm{W}$ & $\mathrm{P}$ & \\
\hline & C & A & $\mathrm{C}$ & $\mathrm{W}$ & W & $P$ & $\mathrm{C}$ & \\
\hline W & $\mathrm{C}$ & $\mathrm{W}$ & $\mathrm{A}$ & $P$ & $\mathrm{C}$ & W & $\mathrm{W}$ & $\mathrm{C}$ \\
\hline $\mathrm{C}$ & A & $\mathrm{C}$ & W & $\mathrm{P}$ & $\mathrm{P}$ & A & $\mathrm{C}$ & $\mathrm{P}$ \\
\hline
\end{tabular}

Viewpoint 3: Reflective Analysis

\begin{tabular}{|c|c|c|c|c|c|c|c|c|}
\hline & & & & & & & & \\
\hline & & & & $\mathrm{C}$ & & & & \\
\hline & & & W & $P$ & $\mathrm{~A}$ & & & \\
\hline & $\mathrm{C}$ & A & $\mathrm{P}$ & A & $\mathrm{P}$ & A & W & \\
\hline & $\mathrm{P}$ & $\mathrm{P}$ & A & W & $\mathrm{C}$ & A & W & \\
\hline $\mathrm{C}$ & $\mathrm{C}$ & C & $P$ & $P$ & W & A & W & W \\
\hline $\mathrm{C}$ & $\mathrm{C}$ & A & $\mathrm{C}$ & $\mathrm{p}$ & W & W & $\mathrm{P}$ & A \\
\hline
\end{tabular}

Key: $\mathrm{A}=$ Analytical; $\mathrm{C}=$ Creative; $\mathrm{P}=$ Practical; $\mathrm{W}=$ Wisdom 


\section{Discussion}

The present study offers insights into the way that students perceive their own learning style and the way that they perceive their learning environments. A particularly interesting result is the perceived incongruence for six of the nine participating students between their own learning style and that of the classes they take. One reason this is interesting is that college students self-select (to some extent) the courses in which they enroll, so the incongruence might be expected to occur at a lower level as students can simply take courses they perceive as being more aligned with their way of learning. The perception of course learning style is also not homogenous - it spans all three learning styles. So, it appears that some students perceive courses as being taught in each of the three 'types'. This leads to the question of why students choose to enroll in courses or fields of study that are incongruous to their own style of learning. Future research can address this issue.

Some students perceived the classroom environment as congruous with their own learning style, however. This finding points to the idea that teaching techniques may be reaching only some of the students. Using a variety of teaching techniques may allow educators to reach a wider range of students in their classes. Future research should address the effect of increasing variety in teaching techniques not only on perceived congruence, but also on learning and developmental outcomes.

It is worthwhile to note that, although Sternberg's thinking styles were useful to structure the concourse, they were only somewhat related to the way that students perceived their own learning and the way that their classes are taught. This suggests Sternberg's theory only partially explains student's views of learning style. In place of Sternberg's creative type, the Social Imagination viewpoint emerges. It has the element of creativity, but with a distinctly social aspect. The creativity in this viewpoint serves a social purpose, and is rooted in social reality. This is quite distinct from Sternberg's idea of creativity, and appears to merge some ideas from the wisdom type, while maintaining a distinct nature. The Individualized Practical Understanding viewpoint seems to share some similarity with the practical type from Sternberg's theory, but also shows a distinct character. It has an individual nature, pulling away from social understandings of learning, and also shows an analytic nature to the practical application, thus merging some ideas from Sternberg's analytic type. The Reflective Analysis vicwpoint seems to merge both the analytic and practical types from Sternberg's theory. The students' perspective merges theoretical constructs in a more dynamic way giving a nuanced understanding of learning not accessible in the thinking styles theory.

The results of this study are tentative and exploratory. The sample size used is somewhat smaller than typical for a Q method study, and included a total of only 18 sorts on 36 items. A larger sample might produce different results, or substantiate a fourth viewpoint in the factor analysis. Further, these results should be further explored with other methods to explore the student perspective on learning styles and learning environments including interviews, person-centered quantitative analysis, and Q-methodology studies using other Q-sets related to learning and instructional methods. These methods will provide a richer picture of the student perspective on learning and learning environments, and will provide more information on the way students perceive congruence or incongruence between their own style of learning and the environments in which they learn.

\section{Conclusions}

However, an implication of this research is that teachers can perhaps be more adaptable in their teaching style so that students of diverse learning styles are more able to perceive congruity between themselves and the learning environment. For example, four education majors participated, and their perceptions of their own learning style loaded across all three viewpoints, suggesting that learning style is not a 
function of college major. That is, education professors cannot expect to teach in one style because education students will leam in that mamer. The same is likely true of other majors as well. Therefore, instnctors might consider being more adaptable in teaching methods, including a variety of styles in their courses to give students ways to connect with course content. This has been the suggestion of Stemberg and Zhang (2005) who suggest that thinking styles can be a basis for differentiating classroom instruction techniques. Others have suggested integrating various styles of teaching and learning for holistic educational development, such as cognitive, psychomotor, creative, and emotional/reflective tasks (Montgomery, Strunk, Steele, and Bridges, 2012).

\section{References}

Brown, S. R. (1980). Political subjectivity. New Haven, CT: Yale University Press.

Grigorenko, E. L., Stemberg, R. J. (1997). Styles of thinking, abilities, and academic performance. Exceptional Children, 63(3), 295-312.

McKeown, B., \& Thomas, D. (1988). Q Methodology. Newbury Park, CA: Sage Publications.

Montgomery, D., Strunk, K., Steele, M,. \& Bridges, S. (2012). Jungian typology as holistic teaching strategy in higher education. Encounter, 25(4) 64-72.

Murphy, A., \& Janeke, H.C. (2009). The relationship between thinking styles and emotional intelligence: An exploratory study. South African Journal of Psychology, 39(3), 357- 375.

O'Hara, L. A., \& Sternberg, R. J. (2001). It doesn't hurt to ask: Effects of instnuctions to be creative, practical, or analytic on essay-writing performance and their interaction with students' thinking styles. Creativity Research Journal, 13(2), 197-210.

Stephenson, W. (1953). The study of behavior: Q-technique and its methodology. Chicago, IL: University of Chicago Press.

Stemberg, R. J. (2001). Why school should teach for wisdom: The balance theory of wisdom in educational settings. Educational Psychologist, 36(4), 227-245.

Stemberg, R. J. (2004). Why smart people can be so foolish. European Psychologist, 9(3), 145- 150.

Sternberg, R. J., Castejon, J. L., Prieto, M. D., Hautamaki, J., \& Grigorenko, E. L. (2001). Confimatory factor analysis of the Stemberg triarchic abilities test in three intemational samples: An empirical test of the triarchic theory of intelligence. European Joumal of Psychological Assessment, 17(1), 1-16.

Sternberg, R. J., \& Grigorenko, E. L. (1993). Thinking styles and the gifted. Roeper Review, $16(2), 122-131$.

Sternberg, R. J., Grigorenko, E. L., \& Zhang, L. F. (2008). Styles of leaming and thinking matter in instruction and assessment. Perspectives on P'sychological Science, 3,486-506.

Sternberg, R. J., Reznitskaya, A., \& Jarvin, L. (2007). Teaching for wisdom: What matters is not just what students know but how they use it. London Review of Education, 5(2), 143- 158.

Sternberg, R. J., \& Zhang, L. F. (2005). Styles of thinking as a basis of differentiated instruction. Theory Into Practice, 44(3), 245-253.

Zhang, L. F. (2004). Revisiting the predictive power of thinking styles for academic performance. The Journal of Psychology, 138(4), 351-370.

Zhang, L. F., \& Sternberg, R. J. (2002). Thinking styles and teachers' characteristics. International Journal of Psychology, 37(1), 3-12.

Zhang, L., Sternberg, R. J., \& Rayner, S. (2012). Handbook of intellectual styles: Preferences in cognition, learning, and thinking. New York, NY: Springer. 